\title{
Neuronal Formation of Free Radicals Plays a Minor Role in Hypoxic Cell Death in Human NT2-N Neurons
}

\author{
RUNAR ALMAAS, OLA DIDRIK SAUGSTAD, DAVID PLEASURE, AND TERJE ROOTWELT \\ Department of Pediatric Research, National Hospital, Oslo, Norway [R.A., O.D.S., T.R.], and Neurology \\ Research, Children's Hospital of Philadelphia, Philadelphia, Pennsylvania, U.S.A. [D.P.]
}

\begin{abstract}
Free radicals are suggested to play an important role in hypoxic-ischemic neuronal death. However, the importance in human disease is not known. Furthermore, whether posthypoxic free radical formation mainly occurs in endothelium and neutrophils, or whether neuronal production is important, is not finally determined. To study this we differentiated human Ntera2 teratocarcinoma cells into postmitotic NT2-N neurons and exposed them to free radicals, hypoxia, or oxygen and glucose deprivation. These cells are devoid of nitric oxide synthase, and we hypothesized that free radicals are important mediators downstream of $N$-methyl-D-aspartate stimulation. Production of free radicals, evaluated with the fluorescent dyes dihydrorhodamine and 2',7'-dichlorodihydrofluorescein, was significantly higher in neurons deprived of oxygen and glucose after $40 \mathrm{~min}$ of reoxygenation than in normoxic cells. The antioxidant trolox, the flavonoid quercetin, thiopental, and the $N$-methyl-D-aspartateglutamate receptor antagonist MK-801 reduced the formation of free radicals. Treatment with the flavonoid rutin $(86 \pm 16 \%$ of hypoxic cells without drug, $p<0.01)$, trolox $(86 \pm 20 \%, p<$ $0.01)$, and MK-801 $(57 \pm 12 \%, p<0.01)$ reduced lactate dehydrogenase release after $6 \mathrm{~h}$ of hypoxia. Trolox, salicylate, and quercetin also significantly reduced lactate dehydrogenase release after $3 \mathrm{~h}$ of oxygen and glucose deprivation. The protection offered by these antioxidants was, however, limited com-
\end{abstract}

pared with the effect of MK-801. We conclude that oxygen and glucose deprivation causes a moderate increase in the formation of free radicals in NT2-N neurons that can be inhibited by antioxidants and by blocking of the $N$-methyl-D-aspartateglutamate receptor. Although MK-801 conveys profound protection, antioxidants provide only a limited improvement in neuronal survival. Thus in this model, mechanisms downstream of the $\mathrm{N}$-methyl-D-aspartate-glutamate receptor other than free radicals and nitric oxide have to be invoked. (Pediatr Res 51: 136-143, 2002)

DHR, dihydrorhodamine

\section{Abbreviations}

LDH, lactate dehydrogenase

MTT, 3-[4,5-dimethylthiazol-2-yl]-2,5-diphenyltetrazolium bromide

NMDA, $N$-methyl-D-aspartate

NO, nitric oxide

NOS, nitric oxide synthase

SIN-1, 3-morpholinosydnonimine

SNAP, $S$-nitroso- $N$-acetylpenicillamine

SOD, superoxide dismutase

DMEM, Dulbecco's modified Eagle medium

DCF-H $\mathbf{H}_{2}, 2^{\prime}, 7^{\prime}$-dichlorodihydrofluorescein diacetate
Several experiments have indicated a role for free radicals in the pathogenesis of hypoxic-ischemic cell death. The xanthine oxidase inhibitor and hydroxyl radical scavenger allopurinol reduces hypoxic-ischemic brain damage in rats (1), and van Bel et al. (2) demonstrated beneficial effects of allopurinol in asphyxiated infants. Infarct size and brain edema after focal cerebral ischemia are attenuated in adult transgenic mice over-

Received March 23, 2001; accepted October 11, 2001.

Correspondence and reprint requests: Runar Almaas, M.D., Department of Pediatric Research, The National Hospital, N-0027 Oslo, Norway; e-mail: runaralm@start.no

Runar Almaas is a fellow at the University of Oslo (Norway). This project was also supported by the Norwegian Research Council, the Norwegian Society for Cardiovascular Diseases, The Laerdal Foundation for Acute Medicine, The Norwegian Air Ambulance, Medinnova, Odd Fellow, Malthes legacy, and by grants from Rolf Geir Gjertsen's Foundation, Bull's Foundation, and Carl Semb's Foundation. expressing CuZn SOD (3). However, brain injury after hypoxia-ischemia was exacerbated in a similar newborn mice model (4).

During reperfusion after cerebral ischemia in pigs, superoxide anion is generated (5). Production of free radicals after ischemia has been reported from rat brain microvessels (6) and from fetal bovine endothelial cells (7). A substantial part of posthypoxic free radical formation in endothelium has been attributed to xanthine oxidase (7). On the other hand, ScmidElsaesser et al. (8) demonstrated superior neuroprotective efficacy of an aminosteroid with presumed improved potential to enter the brain parenchyma compared with an aminosteroid predominantly acting on the endothelium of the cerebral vasculature. Whether this aminosteroid also possessed superior 
abilities to reach radical formation sites inside the endothelium was not determined. Thus, whether significant free radical formation occurs in the neurons themselves, or whether the major production site is the vascular endothelium or activated neutrophils (9), is not finally determined.

The mechanisms of hypoxic neuronal cell death have been studied mostly with the use of fetal rat or mouse neurons. Posthypoxic free radical formation has been measured in neonatal rat cervical ganglia neurons (10), in fetal forebrain rat neurons (11), in rat pheochromocytoma PC12 cells (12), and in mouse cortical neurons (13). However, there are species differences that make extrapolation of data to humans difficult. The importance of species differences was recently highlighted when tumor-necrosis-factor-related ligand was shown to induce apoptosis in the human brain. This potential cancer therapy drug was believed to be safe as it did not cause damage in laboratory animals (14). One relevant difference when studying free radicals is the presence of xanthine oxidase in rat neurons $(15-17)$ in contrast to the absence of this radicalproducing enzyme in human neurons (18). As far as we know posthypoxic formation of free radicals has not previously been evaluated in cultured human neurons.

Human NT2-N neurons are derived from a human teratocarcinoma cell line. After treatment with retinoic acid for 5-6 wk and mitotic inhibitors for $3 \mathrm{wk}$, these cells develop into stable, polarized, neuronlike postmitotic cells (19). The NT2-N neurons are allowed to grow for $4 \mathrm{wk}$ after last replating, and during this period they develop an extensive network of neuritic processes that can be identified as axons or dendrites. They express several CNS neuronal marker proteins (20), express functional non-NMDA and NMDA receptors $(21,22)$, and contain synaptic vesicle-associated proteins (23).

We have established a model with hypoxic hypoxia in these cells and shown that hypoxic neuronal cell death could be reduced by hypothermia, by treatment with the NMDAreceptor blocker MK-801, or by the $\alpha$-amino-3-hydroxy-5methyl-4-isoxazolepropionic acid antagonist CNQX (24). The NT2-N neurons are devoid of NOS (25), and $N^{\mathrm{w}}$-nitro-larginine methyl ester is not protective during hypoxia (24), so mechanisms other than NO downstream of NMDA stimulation have to be sought. We have previously found significant correlations between the in vitro antioxidative properties of different barbiturates and their neuroprotective effects in this model (26). We therefore hypothesized that hypoxic NT2-N neurons generate free radicals during reoxygenation and that posthypoxic cell death could be reduced by treatment with antioxidants.

\section{METHODS}

Materials. Deferoxamine mesylate, bovine SOD (EC 1.15.1.1), SIN-1, SNAP, MTT, catalase (EC 1.11.1.6), quercetin, rutin, sodium salicylate, and glutamate were purchased from Sigma Chemical Co. (St. Louis, MO, U.S.A.). Trolox (Aldrich Chemical Company, Inc, Milwaukee, WI, U.S.A.), MK-801 (Research Biochemicals Internationals, Natick, MA, U.S.A.), and thiopental sodium (Abbott Laboratories, North
Chicago, IL, U.S.A.) were also tested. Deionized water (Millipore, Bedford, MA, U.S.A.) was used in buffers or as solute.

Hypoxia-reoxygenation. NT2 cells were prepared as previously described (26). Two or 3 million cells per well (in 12-well plates, Corning Inc, Corning, NY, U.S.A.) were used for the hypoxia study and the oxygen-glucose deprivation study, respectively.

The hypoxia experiments were started 3 to $7 \mathrm{~d}$ after the last feeding. On the day of the experiment, each well was examined microscopically at least $30 \mathrm{~min}$ before use, and then returned to the incubator. DMEM with or without glucose, with 100 $\mathrm{IU} / \mathrm{mL}$ penicillin and $100 \mu \mathrm{g} / \mathrm{mL}$ streptomycin, was bubbled for 10 min with $5 \% \mathrm{CO}_{2}$ and $95 \% \mathrm{~N}_{2}$ and heated to $37^{\circ} \mathrm{C}$. Immediately before the experiment the cells were washed twice with $0.5 \mathrm{~mL}$ of PBS, and $0.5 \mathrm{~mL}$ of deoxygenated medium was added to each well. Five microliters of concentrated drug solution was added as indicated to each well, and the cells were placed in a preheated, humid anaerobic chamber (GasPak 150, Becton Dickinson, Cockeysville, MD, U.S.A.). Vacuum was applied to the chamber for $20-25$ s $(20-25$ inches of $\mathrm{Hg}$ ), and the air replaced with $5 \% \mathrm{CO}_{2}$ and $95 \% \mathrm{~N}_{2}$. This procedure was performed four times. Inside the chamber hydrogen was generated with a GasPak Plus envelope containing palladium catalyst to remove trace amounts of oxygen (Becton Dickinson). With this procedure oxygen concentration is $0.1 \%$ after the fourth gas exchange, and falls to $<0.1 \%$ within 30-60 min and remains $<0.1 \%$ for at least $6 \mathrm{~h}(26)$. The chamber was placed in an incubator for $3 \mathrm{~h}$ (combined glucose and oxygen deprivation) or $6 \mathrm{~h}$ (hypoxia only). Temperature was monitored continuously inside the anaerobic chamber and in the incubator, and the cells were not exposed to temperatures above $38^{\circ} \mathrm{C}$. After hypoxia the cells were reoxygenated and returned to the normoxic incubator until $24 \mathrm{~h}$ after start of the hypoxic exposure. At reoxygenation $5 \mu \mathrm{L}$ of glucose (final concentration, $5.5 \mathrm{mM}$ ) was added to each well exposed to combined glucose and oxygen deprivation. As MK-801 offers almost complete protection in this hypoxia model $(24,26)$, at least one well was treated with $10 \mu \mathrm{M}$ MK-801, prepared as $1 \mathrm{mM}$ stock in deionized water, in all experiments as a positive treatment control. Cells were treated with (all final concentrations) $1.5 \mathrm{mM}$ deferoxamine mesylate, $500 \mathrm{U} / \mathrm{mL}$ SOD, $5 \mathrm{mM}$ salicylate, $1 \mathrm{mM}$ SNAP, or $200 \mu \mathrm{M}$ thiopental. Trolox $(160 \mu \mathrm{M}$ or $400 \mu \mathrm{M})$ prepared in alkaline solutions was used in the hypoxia and the oxygen-glucose deprivation studies, respectively. Rutin $(4 \mu \mathrm{M})$ was prepared as a $400 \mu \mathrm{M}$ alkaline solution (pH of the cell medium was not affected by the addition of this) and used in the hypoxia experiments. Stock solutions of quercetin $(50 \mathrm{mM})$ and rutin $(50 \mathrm{mM})$ were prepared in DMSO, and $0.5 \mu \mathrm{L}$ of stock was added to $500 \mu \mathrm{L}$ of medium in the oxygen and glucose deprivation study. DMSO diluted 1/1000 does not affect LDH release in this model (24).

Exposure of NT2 cells to SIN-1. SIN-1 is a compound that releases superoxide anion radical and NO continuously on its decomposition, with concomitant production of peroxynitrite. NT2 neurons were washed twice with PBS and $500 \mu \mathrm{L}$ of DMEM (without HEPES) with $5.5 \mathrm{mM}$ glucose, $100 \mathrm{IU} / \mathrm{mL}$ penicillin, and $100 \mu \mathrm{g} / \mathrm{mL}$ streptomycin added to each well. 
SIN-1 was dissolved in deionized water immediately before addition to NT2 cells (final concentration, $3 \mathrm{mM}$ ). The following antioxidants were tested in this model (all final concentrations): $100 \mathrm{U} / \mathrm{mL}$ catalase, $50 \mu \mathrm{M}$ quercetin, $50 \mu \mathrm{M}$ rutin, or $400 \mu \mathrm{M}$ trolox.

LDH assay. Cell viability was assessed by measuring LDH activity in the supernatant. The remaining cells were lysed with cold deionized water, and LDH was analyzed in the lysate to assure that total LDH activity was in a similar range in all wells. LDH was assayed with a kit (No 1644 793, Boehringer Mannheim GmbH, Mannheim, Germany). The measurements were performed at $492 \mathrm{~nm}$ in a Titertek Multiskan Plus MK11 ELISA-reader connected to a computer with the program GENESIS (both from Labsystems and Life Sciences International Ltd, Helsinki, U.K.). Whereas neither salicylate, trolox, rutin, quercetin, nor MK-801 affected the LDH assay, both deferoxamine and SOD significantly inhibited LDH activity in control measurements. We have previously shown that LDH release into the supernatant correlates well with a fluorescent cytotoxicity assay in this model (24).

MTT assay. To determine cell viability we used an MTT assay as well. MTT $(0.5 \mathrm{mg} / \mathrm{mL})$ dissolved in PBS containing $5.5 \mathrm{mM}$ glucose was prepared immediately before use. After $24 \mathrm{~h}$ the medium was aspirated, and $0.5 \mathrm{~mL}$ of the MTT solution was added. The plates were then returned to the incubator. After $60 \mathrm{~min}$ the medium was aspirated and replaced with $0.5 \mathrm{~mL}$ of DMSO to dissolve the salt produced by cleavage of MTT. Absorbance was read at $570 \mathrm{~nm}$ and background at $660 \mathrm{~nm}$ was subtracted, using the same system as described above.

Oxygen radical production. DHR-123 (Molecular Probes, Eugene, OR, U.S.A.) was dissolved in DMSO at a concentration of $500 \mu \mathrm{M}$, and aliquots were stored in deoxygenated containers at $-20^{\circ} \mathrm{C}$ and protected from light. Ten microliters of this stock was added to $10 \mathrm{~mL}$ of DMEM immediately before reoxygenation. At reoxygenation $500 \mu \mathrm{L}$ of DMEM with DHR-123 and glucose $(5.5 \mathrm{mM})$ replaced the aglycemic medium used during combined oxygen and glucose deprivation, and the first reading was performed. Fluorescence (485 $\mathrm{nm} / 535 \mathrm{~nm})$ was measured with Victor 1420 Multilabel Counter (Wallac Oy, Turku, Finland). The cells were then returned to the normoxic incubator, and new measurements were performed after 40,80 , and $120 \mathrm{~min}$. Values were related to the first reading ( $0 \mathrm{~min}$ reoxygenation).

Stock solution $(10 \mathrm{mM})$ of DCF- $\mathrm{H}_{2}$ (Molecular Probes) in PBS was stored at $-70^{\circ} \mathrm{C}$. At reoxygenation the aglycemic medium was replaced with medium containing $10 \mu \mathrm{M} \mathrm{DCF}-\mathrm{H}_{2}$ and $5.5 \mathrm{mM}$ glucose. The cells were loaded with $\mathrm{DCF}-\mathrm{H}_{2}$ for $40 \mathrm{~min}$ and then washed twice with PBS, before medium with $5.5 \mathrm{mM}$ glucose without DCF- $\mathrm{H}_{2}$ was added. The first reading was then performed. Fluorescence $(485 \mathrm{~nm} / 535 \mathrm{~nm})$ was measured with Victor 1420 Multilabel Counter. New measurements were performed 80 and $120 \mathrm{~min}$ after the end of hypoxia. Hypoxic and normoxic experiments were performed in pairs, and all values were related to the first reading ( $40 \mathrm{~min}$ of reoxygenation) of the normoxic cells.

Hypoxanthine. Supernatants were collected $24 \mathrm{~h}$ after start of hypoxia and frozen at $-20^{\circ} \mathrm{C}$. High-performance liquid chromatography was performed on a reversed-phase $\mathrm{C} 18$ column (Pecosphere-5C C18, $0.46 \times 15.0 \mathrm{~cm}$ (Perkin Elmer Company, Norwalk, CT, U.S.A.) as described previously (27). A buffer of $0.01 \mathrm{M} \mathrm{KH}_{2} \mathrm{PO}_{4}(\mathrm{pH} 4.2)$ was used as the mobile phase, with a flow rate of $0.8 \mathrm{~mL} / \mathrm{min}$. The eluting compounds were detected at $254 \mathrm{~nm}$.

Statistical analysis. MTT cleavage, hypoxanthine in the supernatant, and LDH release to the supernatant in the treatment groups were calculated in percent of unprotected hypoxic or oxygen-glucose-deprived cells in the same experiment. Mean and SD from at least six to eight wells from at least three to four different experiments are given unless otherwise specified.

Treatments were compared with untreated hypoxia by ANOVA and Dunnett's post hoc test. Comparison of fluorescence in normoxic neurons and cells exposed to oxygen and glucose deprivation was performed with an unpaired $t$ test with Welch correction. Time development of fluorescence was tested with repeated measurements ANOVA. A two-tailed $p<$ 0.05 was considered statistically significant. Analyses were performed with a GraphPad INSTAT tm/PC statistical package (San Diego, CA, U.S.A.). For the repeated measurements ANOVA, StatView for Windows was used (SAS Institute Inc., Cary, NC, U.S.A.).

\section{RESULTS}

Exposure to SIN-1. Human NT2-N neurons were incubated with the peroxynitrite-releasing compound SIN-1 to study whether these neurons were susceptible to free radicals. Exposure of NT2-N neurons to $3 \mathrm{mM} \mathrm{SIN-1} \mathrm{led} \mathrm{to} \mathrm{pronounced} \mathrm{cell}$ death evaluated microscopically and by an increase in LDH release [from $6.0 \pm 2.0 \%$ in untreated controls to $34 \pm 13 \%$ (LDH supernatant/LDH total)]. The water-soluble vitamin $\mathrm{E}$ analog trolox $(400 \mu \mathrm{M})$, catalase $(100 \mathrm{U} / \mathrm{mL})$, and the flavonoids rutin $(50 \mu \mathrm{M})$ and quercetin $(50 \mu \mathrm{M})$ markedly attenuated SIN-1-induced cytotoxicity (Fig. 1). Ten micromolar MK-801 had no effect. The neurons were also incubated with the fluorescent dye DHR-123, and fluorescence was measured after 40 min. SIN-1 strongly increased fluorescence (674 \pm $17 \%$ increase in fluorescence, $n=5$ ), and this could be inhibited by $50 \mu \mathrm{M}$ quercetin $(154 \pm 5.3 \%$ increase in fluorescence, $n=5$ ). These experiments demonstrate that SIN-1 increases cell death in NT2-N neurons produces free radicals that could be scavenged by antioxidants, and that antioxidants protect the neurons from SIN-1.

Hypoxia. As the NT2-N neurons were susceptible to externally applied free radicals and could be rescued by antioxidants, we tested the protective effect of antioxidants after hypoxia. With $6 \mathrm{~h}$ of hypoxia and $18 \mathrm{~h}$ of reoxygenation, 18.4 $\pm 5.6 \%$ of the cells died (LDH supernatant/LDH total). LDH release was significantly reduced in wells treated with MK-801 (Fig. 2). Treatment with $160 \mu \mathrm{M}$ trolox and $4 \mu \mathrm{M}$ rutin both significantly inhibited LDH release (Fig. 2).

The glutamate level in the supernatant of these cells during hypoxia varies somewhat among the different cultures (24). Addition of $100 \mu \mathrm{M}$ glutamate concomitant with the start of hypoxia to achieve a certain level of glutamate in all wells 


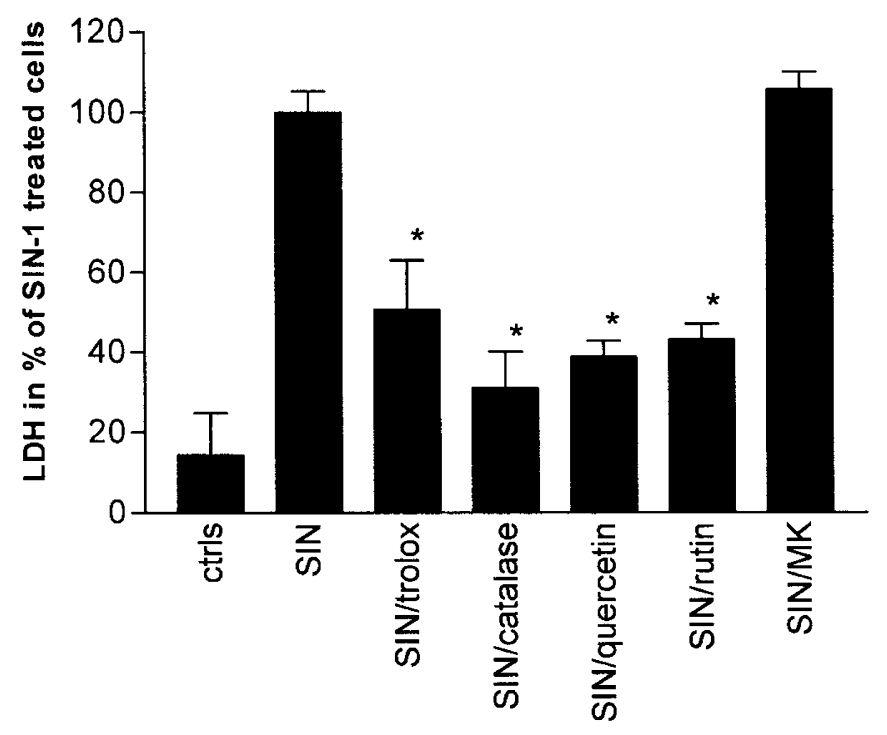

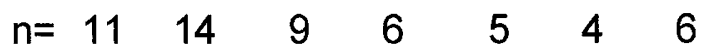

Figure 1. NT2-N neurons exposed to $3 \mathrm{mM}$ SIN-1 (SIN). Samples were treated with $400 \mu \mathrm{M}$ trolox, $100 \mathrm{U} / \mathrm{mL}$ catalase, $50 \mu \mathrm{M}$ quercetin, $50 \mu \mathrm{M}$ rutin, or $10 \mu \mathrm{M}$ MK-801 $(M K)$. LDH in supernatant was measured after $24 \mathrm{~h}$ and normalized to SIN-1-treated wells in the same experiment. Mean and SD are given. $* p<0.01$ vs SIN-1-treated neurons.

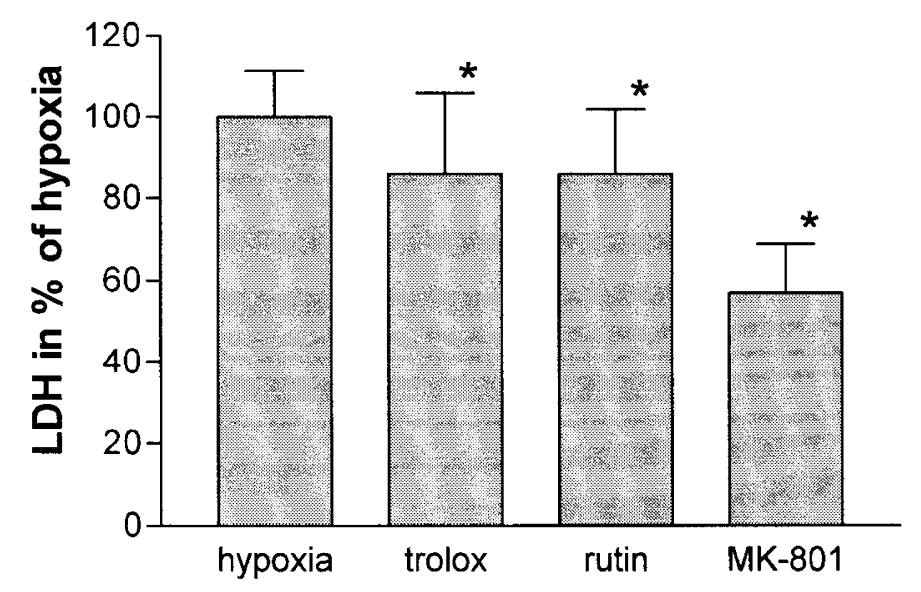

Figure 2. LDH release into the supernatant after $6 \mathrm{~h}$ of hypoxia and $18 \mathrm{~h}$ of reoxygenation. Neurons were treated with $160 \mu \mathrm{M}$ trolox, $4 \mu \mathrm{M}$ rutin, or 10 $\mu \mathrm{M}$ MK-801 immediately before hypoxia. Values are normalized to hypoxic samples $(100 \%)$ in each experiment. Mean and SD are given. ${ }^{*} p<0.01$ vs untreated hypoxic controls.

resulted in more pronounced cell death. After 24 h, $25.4 \pm$ $7.1 \%$ of LDH was released to the supernatant. Although the relative effect of MK-801 (39 $\pm 7.8 \%$ of untreated hypoxic controls, $n=6, p<0.01$ ) was even more pronounced in this model, no effects of trolox ( $99 \pm 14 \%$ of untreated hypoxic controls, $n=9)$ or rutin $(104 \pm 16 \%, n=9)$ were now seen.

Combined oxygen and glucose deprivation. As hypoxia for $6 \mathrm{~h}$ provided rather limited neuronal death, we also exposed the NT2-N neurons to combined oxygen and glucose deprivation for $3 \mathrm{~h}$ and then reoxygenated the cells in the presence of glucose until $24 \mathrm{~h}$ after start of hypoxia. After $24 \mathrm{~h}, 38.9 \pm$ $5.3 \%$ of total LDH was released to the supernatant, compared with $8.2 \pm 2.5 \%$ in normoxic controls, and $17 \pm 1.5 \%$ in normoxic cells treated with a sham vacuum-flushing proce- dure. Treatment with the NMDA antagonist MK-801 $(10 \mu \mathrm{M})$ strongly inhibited LDH release (Fig. $3 A$ ) and improved MTT cleavage (Fig. $3 \mathrm{C}$ ) in this model. Salicylate (5 mM), quercetin $(50 \mu \mathrm{M})$, and trolox $(400 \mu \mathrm{M})$ significantly reduced LDH release, whereas rutin $(50 \mu \mathrm{M})$ had no significant effects (Fig. $3 A$ ). However, neither of them improved MTT cleavage significantly (Fig. 3C). The antioxidant enzyme SOD and the iron-chelator deferoxamine inhibited the LDH assay, giving falsely low LDH values, and the apparent protection offered by deferoxamine and SOD was an artifact. Previously, we have found a high correlation between the ATP breakdown product hypoxanthine and LDH release after $24 \mathrm{~h}$ (26). Both MK-801 and quercetin significantly reduced hypoxanthine in the supernatant compared with untreated oxygen- and glucose-deprived cells (Fig. 3B).

NT2-N neurons have previously been demonstrated to lack NOS (25), and, to mimic a situation in vivo in which a subpopulation of neurons produce NO toxic to neighboring cells, neurons deprived of oxygen and glucose were also exposed to the NO-releasing agent SNAP immediately before hypoxia. This resulted in a $43 \%$ increase in cell death (from $33.6 \pm 6.0 \%$ to $48 \pm 8.3 \% \mathrm{LDH}$ release) compared with oxygen- and glucose-deprived neurons not exposed to NO. Trolox $(92 \pm 8.7 \%, p<0.05, n=9)$ and quercetin $(91 \pm$ $12 \%, p<0.01, n=12)$ offered slight, but significant, protection in this model also, measured as a reduction in $\mathrm{LDH}$ release.

Production of free radicals after combined oxygen and glucose deprivation. Formation of free radicals was evaluated with DHR-123 at 0, 40, 80, and 120 min after start of reoxygenation in oxygen- and glucose-deprived NT2-N neurons and in normoxic cells exposed to vacuum and flushing with $21 \%$ oxygen. The production of free radicals increased with time during the first $120 \mathrm{~min}$ of reoxygenation $(p<0.0001)$, and there was a significant difference $(p<0.02)$ between normoxic and oxygen- and glucose-deprived cells (Fig. 4). At $40 \mathrm{~min}$ there was significantly higher fluorescence $(p<0.01)$ in hypoxic neurons than in normoxic controls (Fig. 4). From 40 to $120 \mathrm{~min}$ of reoxygenation, fluorescence did not develop differently, indicating that the increased posthypoxic formation of free radicals took place in the early reoxygenation period. Trolox, quercetin, and MK-801 significantly $(p<0.01)$ reduced production of free radicals at $40 \mathrm{~min}$ of reoxygenation (Fig. 5). Furthermore, the barbiturate thiopental $(200 \mu \mathrm{M})$, which we have previously found both to scavenge hydroxyl radicals and inhibit lipid peroxidation and to protect the NT2-N neurons from hypoxia (26), also significantly $(p<0.01)$ reduced DHR-123 fluorescence (Fig. 5).

Free radicals were also measured with the fluorescent dye DCF-H ${ }_{2}$. Fluorescence increased with time $(p<0.0001)$ during the first $120 \mathrm{~min}$ of reoxygenation in hypoxic cells loaded with $\mathrm{DCF}-\mathrm{H}_{2}$. After $40 \mathrm{~min}$, fluorescence was significantly higher in hypoxic cells than in normoxic controls $(142 \pm 34 \%$ of fluorescence of normoxic controls, $n=9, p=0.006$ ). As for DHR-123, there were no significant differences in the increase in fluorescence between hypoxic and normoxic cells from 40 to 120 min of reoxygenation $(p=0.45)$. 

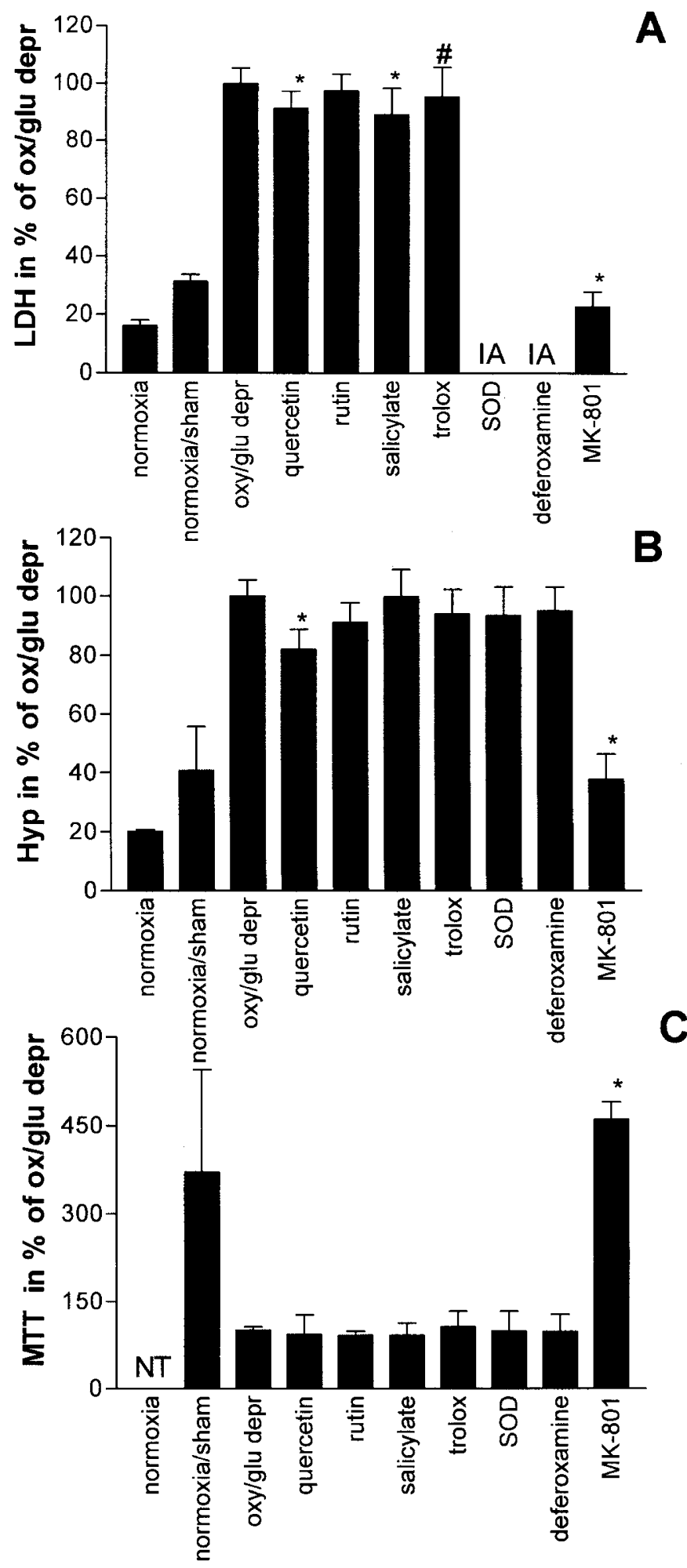

Figure 3. Neuroprotective effects of treatment with antioxidants and MK-801 on combined oxygen and glucose deprivation for $3 \mathrm{~h}$. The protective effects of $50 \mu \mathrm{M}$ quercetin, $50 \mu \mathrm{M}$ rutin, $5 \mathrm{mM}$ salicylate, $400 \mu \mathrm{M}$ trolox, $500 \mathrm{U} / \mathrm{mL}$ SOD, $1.5 \mathrm{mM}$ deferoxamine, and $10 \mu \mathrm{M}$ MK- 801 were tested. Cell death was evaluated by measuring LDH $(A)$ or hypoxanthine $(H y p, B)$ in the supernatant and as MTT cleavage $(C)$. Treated samples are expressed as percent of untreated oxygen- and glucose-deprived (ox/glu depr) cells $24 \mathrm{~h}$ after the start of the insult. Mean and SD are given. NT, not tested; $I A$, interfered with the LDH assay and values not reported. ${ }^{*} p<0.01 v s$ untreated oxygen- and glucose-deprived controls. $\# p<0.05$ vs untreated oxygen- and glucosedeprived controls.

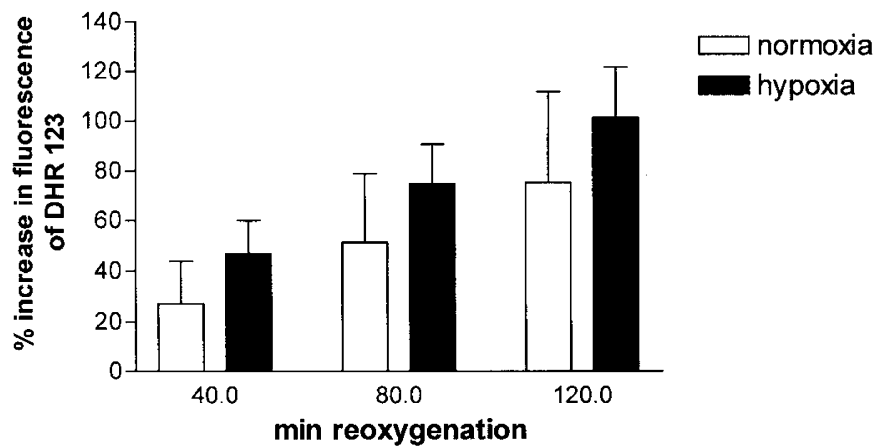

Figure 4. Production of reactive oxygen species during the first $120 \mathrm{~min}$ of reoxygenation after $3 \mathrm{~h}$ of combined oxygen and glucose deprivation measured as conversion of DHR-123 to the fluorescent rhodamine-123. Fluorescence significantly increased with time $(p<0.0001)$, and significant group $(p<$ $0.02)$ and group-by-time differences $(p=0.004)$ were found between cells exposed to combined oxygen and glucose deprivation $(n=12)$ and normoxic cells exposed to vacuum and flushing with $21 \%$ oxygen $(n=10)$.

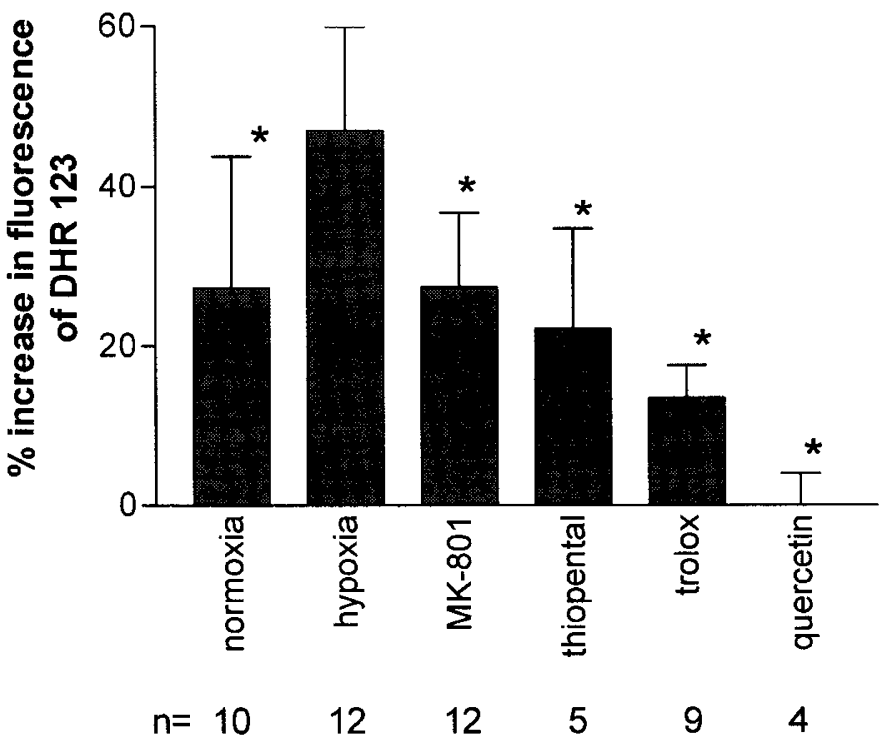

Figure 5. Production of reactive oxygen species after $3 \mathrm{~h}$ of combined oxygen and glucose deprivation measured as conversion of DHR-123 to rhodamine123. All values are related to starting values ( 0 min reoxygenation). At $40 \mathrm{~min}$ of reoxygenation, fluorescence was significantly inhibited by trolox $(400 \mu \mathrm{M})$, quercetin $(50 \mu \mathrm{M})$, thiopental $(200 \mu \mathrm{M})$, and MK-801 (10 $\mu \mathrm{M}) .{ }^{*} p<0.01 v \mathrm{~s}$ unprotected oxygen- and glucose-deprived cells.

\section{DISCUSSION}

In this study we have found that the NT2-N neurons are susceptible to externally applied free radicals. Furthermore, we found a moderate increase in the formation of free radicals during early reoxygenation after combined oxygen and glucose deprivation. This increase in free radical production was measured with two different fluorescence methods, and could be attenuated by treatment with the antioxidants trolox and quercetin. Furthermore, the barbiturate thiopental, which has in vitro antioxidative effects and inhibits neuronal death (26), also inhibited formation of free radicals during reoxygenation. As far as we know this is the first report of formation of free radicals in cultured human neuronlike cells after combined oxygen and glucose deprivation. 
However, even though antioxidants reduced the posthypoxic neuronal free radical formation, their effect on cell death was limited. Partial protection was obtained with only some of the antioxidants, and protection was not demonstrated with all the markers of cell damage. The flavonoid quercetin caused a moderate reduction in LDH release and hypoxanthine accumulation. Trolox and salicylate only inhibited LDH release, whereas the other antioxidants had no effect. None of the antioxidants improved MTT cleavage. In contrast MK-801 had profound effects on LDH release, hypoxanthine accumulation, and MTT cleavage. The protection offered by antioxidants in the hypoxia model tended to be slightly better than in the oxygen- and glucose-deprivation model. Six hours of hypoxia caused less severe cell damage compared with $3 \mathrm{~h}$ of combined oxygen and glucose deprivation. It is possible that the role of endogenous neuronal radical formation is more important in mild long-lasting insults than in more severe insults in which other mechanisms predominate.

One possible explanation for the limited protection by antioxidants in this model could be that these antioxidants were ineffective in detoxifying free radicals. However, we found that they were quite effective in protecting the neurons from SIN1-derived free radicals. On the other hand, externally applied antioxidants may provide more efficient protection against extracellular radicals than against endogenous intracellular radicals. However, the increase in rhodamine fluorescence during reoxygenation was inhibited to a large extent by the tested antioxidants. This does not prove conclusively that free radicals are not important in this model as there might theoretically be free radicals that are not measured by this fluorescence method and were not inhibited. However, several different antioxidants have been tested with similar results. We have also previously found no significant effects of $N$-tert-butyl-ophenylnitrone, the 21 -aminosteroid U74389G, and $\mathrm{N}$-acetyl-Lcysteine in a slightly different hypoxia model (24). Thus we do not believe that the failure of the antioxidants to provide neuronal protection was caused by ineffective free radical scavenging. The increase in DHR-123 fluorescence at $40 \mathrm{~min}$ was an order of magnitude higher in neurons exposed to SIN-1, in which the antioxidants provided significant protection, than in the experiments with oxygen-glucose deprivation. It seems that although there is an increase in endogenous free radical formation after oxygen and glucose deprivation, this increase is too low to contribute substantially to neuronal damage.

The discrepancy between the limited effect of antioxidants in the current model and the pronounced effects in several in vivo animal studies $(1,28)$ may have several explanations. In vivo there are sources of free radicals other than the neurons, such as endothelium, neutrophils, and circulating xanthine oxidase (29). Thus, the finding that the radicals produced by these neurons do not substantially contribute to neuronal death after oxygen and glucose deprivation should not be extended to a conclusion that free radicals are of minor importance in vivo as there are several sources of free radicals other than neurons. Furthermore, how different the NT2-N neurons are from neurons in vivo is not settled. They have, however, been transplanted into rodent brains, where they have survived, matured, and integrated into the host brain for more than $1 \mathrm{y}$ without reverting to a neoplastic state (30). Transplantation of these cells into brains of rats subjected to transient focal ischemia improved passive avoidance task and normalized asymmetrical motor behavior compared with untransplanted controls (31).

The NT2-N neurons are grown for 9 wk before use. Atmospheric oxygen concentration is hyperoxic compared with the concentrations of oxygen in the in vivo brain. This longstanding relative hyperoxia may increase the expression of antioxidants in the culture, making the cultured neurons less susceptible to free radical damage than neurons in vivo. However, application of exogenous peroxynitrite led to substantial cell damage in our model. Furthermore, cultured cells in general have an increased capacity to cover their energy requirement during hypoxia by anaerobic glycolysis compared with neurons in vivo (32). This is reflected in the very modest cell death after $6 \mathrm{~h}$ hypoxia. It is possible that the reduced dependence on aerobic metabolism is accompanied by a lower production of free radicals. Free radicals have, however, been found to have important roles in hypoxia in other cultured neurons, and antioxidants have been shown to protect rodent cultures $(10,13,32,33)$. Species-differences between human neurons and rodent cultures may therefore also be of importance. One species difference is that the vulnerability of fetal human neurons to excitatory amino acids develops over a prolonged time compared with cortical rat neurons (34). The number of NMDA receptors in the mature NT2-N neurons is $1 / 10$ that found in rat brains, but approximately at the same level as that found in fetal human neurons (25). Furthermore, human fetal neurons have a larger capacity of intracellular calciumbuffering systems than cortical rat neurons (35). There are also species differences with respect to the free radical-producing enzyme xanthine oxidase, which is present in rat neurons (15-17) but absent in human brain (18). Transcriptional regulation may account for the species-specific expression of this enzyme, as there are differences in the promotor region of the human and rat genes (36).

The relationship between glutamate and free radicals is complex and tight. Stimulation of NMDA receptors leads to formation of superoxide anion (37) and hydroxyl radicals (38). On the other hand, free radicals may cause an increase in extracellular glutamate both through inhibition of glutamine synthetase (39) and through increase of carrier-mediated release (40). Treatment with antioxidants has been shown to attenuate excitotoxicity exerted by stimulation of NMDA receptors in mice cortical neurons (33). We found that MK-801 inhibited formation of free radicals after combined oxygen and glucose deprivation, indicating NMDA-dependent formation of free radicals after oxygen and glucose deprivation.

As NMDA receptor activation obviously is important in hypoxic NT2-N neurons and glutamate has been demonstrated to stimulate formation of free radicals in several models, one could expect an important role for free radicals as well. However, endogenous production of free radicals seems to be of modest importance in the current model. One reason could be that the stimulation of glutamate receptors after combined oxygen and glucose deprivation was so overwhelming that the relative importance of free radicals was attenuated. In favor of this is the fact that application of glutamate before the start of 
hypoxia increased the relative protection offered by MK- 801 and abolished the effect of antioxidants. Rosenbaum et al. (10) demonstrated that SOD (in combination with $\mathrm{KCl}$ ) inhibited posthypoxic superoxide formation in neonatal rat cervical ganglia neurons and protected these neurons from hypoxia. However, these neurons are devoid of glutamate receptors, and this may have reduced the importance of mechanisms other than free radical formation in neuronal death. Copin et al. (13) reported increased posthypoxic formation of hydrogen peroxide at $5 \mathrm{~h}$, but not at 24 and $48 \mathrm{~h}$, after hypoxia in mouse cortical neurons. Furthermore, they found protection by trolox on posthypoxic neuronal death after $24 \mathrm{~h}$. However, the minor effect of the NMDA antagonist MK-801 indicates a modest role for NMDA receptors in their model as well. In contrast, MK-801 almost fully protected the NT2-N neurons from hypoxia and combined oxygen and glucose deprivation in the present experiment. Free radicals may also attenuate the NMDA-induced increase in intracellular $\mathrm{Ca}^{2+}$ via a redox modulatory site on the NMDA receptor (41). Antioxidants may thus have dual and opposing effects. In models in which NMDA toxicity is important, the protective effects of antioxidants may be masked or lessened by an adverse disinhibition of NMDA receptors. In models in which glutamate receptors are not important, this detrimental effect of antioxidants may not be apparent, and the net effect may be better protection.

In the present model stimulation of glutamate receptors is obviously important. As free radical formation could not be the only downstream mediator of glutamate toxicity, other mechanisms of cell damage downstream of glutamate stimulation have to be considered. Activation of neuronal NOS by calcium and calmodulin is a central mechanism thought to participate in cell injury evoked by glutamate stimulation. In rat cerebellar granula neurons, glutamate-induced excitotoxicity could be inhibited by the NOS inhibitor $N$-nitro-L-arginine and by a phospholipase $\mathrm{A}_{2}$ inhibitor (42). The NT2-N neurons are devoid of NOS (25), and $N^{\mathrm{w}}$-nitro-l-arginine methyl ester (another inhibitor of NOS) is not protective during hypoxia (24). Approximately $1 \%$ of rat neurons and neurons in human cortex express NOS (43). It has been suggested that these cells, which themselves appear to resist the toxicity of $\mathrm{NO}$, may serve as donors of toxic NO to the surrounding neurons, where NO combines with superoxide to form the reactive peroxynitrite. Thus the toxicity of superoxide generated in the NT2-N neurons could be underestimated by the absence of NO, not generated in these neurons or by "vicious" neighbors. Applying exogenous NO by adding the NO donor SNAP markedly increased neuronal death during combined oxygen-glucose deprivation in the present study. Although trolox and quercetin significantly inhibited cell death in the model with NO, the proportion of protection was just marginally higher compared with their effect on oxygen- and glucose-deprived cells in the absence of NO. In contrast, trolox and quercetin markedly protected against SIN-1-generated cytotoxicity in normoxic cells. This could be owing to lack of access of the antioxidants to the intracellular compartment, but in the model with combined oxygen and glucose deprivation, both of them significantly inhibited DHR-123 oxidation. The amount of intrinsic superoxide formation may be too low to produce biologically significant amounts of peroxynitrite, making $\mathrm{NO}$ or other NO products the toxic load rather than peroxynitrite in this setting. This is supported by the finding that NO from SNAP also exerts cytotoxic effects on normoxic NT2 neurons (25).

In conclusion, we have found a significant increase in the production of free radicals after oxygen and glucose deprivation. The formation of free radicals was inhibited by thiopental, by the antioxidants trolox and quercetin, and by the NMDA antagonist MK-801, suggesting NMDA-dependent formation of free radicals. However, whereas inhibition of NMDA receptors had a pronounced protective effect, antioxidants had only limited effects on neuronal survival after combined oxygen and glucose deprivation. Previously, endogenous NO production has been demonstrated not to be important in hypoxic NT2-N cells. Downstream mediators of the glutamate-mediated toxicity other than NO and free radicals thus have to be considered for the major part of the damage caused by hypoxia or combined oxygen-glucose deprivation in these neurons. This does not necessarily rule out a role for free radicals in hypoxicischemic damage, as there are several sources of free radicals other than neurons in vivo. However, in this model with human neuronlike cells, posthypoxic neuronal free radical formation, although present, was not a major mechanism of neuronal damage.

Acknowledgments. The authors thank Irene Ringstad and Hilde Nilsen, Department of Pediatric Research, for excellent technical assistance. We also thank Anne Grindflek for assistance with the fluorescence measurements.

\section{REFERENCES}

1. Palmer C, Vannucci RC, Towfighi J 1990 Reduction of perinatal hypoxic-ischemic brain damage with allopurinol. Pediatr Res 27:332-336

2. van Bel F, Shadid M, Moison RM, Dorrepaal CA, Fontijn J, Monteiro L, van De Bor M, Berger HM 1998 Effect of allopurinol on postasphyxial free radical formation, cerebral hemodynamics, and electrical brain activity. Pediatrics 101:185-193

3. Kinouchi H, Epstein CJ, Mizui T, Chen SF, Chan PH 1991 Attenuation of focal cerebral ischemic injury in transgenic mice overexpressing CuZn superoxide dismutase. Proc Natl Acad Sci USA 88:11158-11162

4. Ditelberg JS, Sheldon RA, Epstein CJ, Ferriero DM 1996 Brain injury after perinatal hypoxia-ischemia is exacerbated in copper/zinc superoxide dismutase transgenic mice. Pediatr Res 39:204-208

5. Armstead WM, Mirro R, Busija DW, Leffler CW 1988 Postischemic generation of superoxide anion by newborn pig brain. Am J Physiol 255:H401-H403

6. Grammas P, Liu G-J, Wood K, Floyd RA 1993 Anoxia/reoxygenation induces hydroxyl free radical formation in brain microvessels. Free Radic Biol Med 14:553557

7. Zweier JL, Kluppusamy P, Lutty GA 1988 Measurement of endothelial cell free radical generation: evidence for a central mechanism of free radical formation in postischemic tissues. Proc Natl Acad Sci USA 85:4046-4050

8. Scmid-Elsaesser R, Zausinger S, Hungerhuber E, Plesnila N, Baethmann A, Reutlen H-J 1997 Superior neuroprotective efficacy of a novel antioxidant (U-101033E) with improved blood-brain barrier permeability in focal cerebral ischemia. Stroke 28:2018-2024

9. Hudome S, Palmer C, Robberts RL, Mauger D, Housman C, Towfighi J 1997 The role of neutrophils in the production of hypoxic-ischemic brain injury in the neonatal rat. Pediatr Res 41:607-616

10. Rosenbaum DM, Kalberg J, Kessler JA 1994 Superoxide dismutase ameliorates neuronal death from hypoxia in culture. Stroke 25:857-863

11. Daval J-L, Ghersi-Egea J-F, Oillet J, Koziel V 1995 A simple method for evaluation of superoxide radical production in neural cells under various culture conditions: application to hypoxia. J Cerebr Blood Flow Metab 15:71-77

12. Höhler B, Lange B, Holzapfel B, Goldenberg A, Hänze J, Sell A, Testan H, Möller W, Kummer W 1999 Hypoxic upregulation of tyrosine hydroxylase gene expression is paralleled, but not induced, by increased generation of reactive oxygen species in PC12 cells. FEBS Lett 457:53-56

13. Copin J-C, Li Y, Reola L, Chan PH 1998 Trolox and 6,7-dinitroquinoxaline-2,3-dione prevent necrosis but not apoptosis in cultured neurons subjected to oxygen deprivation. Brain Res 784:25-36 
14. Nitsch R, Bechman I, Deisz RA, Haas D, Lehmann TN, Wendling U, Zipp F 2000 Human brain-cell death induced by tumor-necrosis-factor-related apoptosis-inducing ligand. Lancet 356:827-828

15. Mueller K, Palmour R, Andrews CD, Knott PJ 1985 In vivo voltammetric evidence of production of uric acid by rat caudate. Brain Res 335:231-235

16. Kinuta Y, Kimura M, Itokawa Y, Ishikawa M, Kikuchi H 1989 Changes in xanthine oxidase in ischemic rat brain. J Neurosurg 71:417-420

17. Desole MS, Miele M, Esposito G, Fresu LG, Migheli R, Zangani D, Sircana S, Grella G, Miele E 1995 Neuronal antioxidant system and MPTP-induced oxidative stress in the striatum and brain stem of the rat. Pharm Biochem Behav 51:581-592

18. Linder N, Rapola J, Raivio KO 1999 Cellular expression of xanthine oxidoreductase protein in normal human tissues. Lab Invest 79:967-974

19. Pleasure SJ, Page C, Lee VM-Y 1992 Pure, postmitotic, polarized human neurons derived from NTera 2 cells provide a system for expressing exogenous proteins in terminally differentiated neurons. J Neurosci 12:1802-1815

20. Pleasure SJ, Lee VM-Y 1993 NTera 2 cells: a human cell line which displays characteristics expected of a human committed neuronal progenitor cell. J Neurosci Res 35:585-602

21. Younkin DP, Tang CM, Hardy M, Reddy UR, Shi QY, Pleasure SJ, Lee VM-Y, Pleasure D 1993 Inducible expression of neuronal glutamate receptor channels in the NT2 human cell line. Proc Natl Acad Sci USA 90:2174-2178

22. Hardy M, Younkin D, Tang CM, Pleasure SJ, Shi QY, Williams M, Pleasure D 1994 Expression of non-NMDA glutamate receptor channel genes by clonal human neurons. J Neurochem 63:482-489

23. Sheridan KM, Maltese WA 1998 Expression of Rab3a GTPase and other synaptic proteins is induced in differentiated NT2N neurons. J Mol Neurosci 10:121-128

24. Rootwelt T, Dunn M, Yudkoff M, Itoh T, Almaas R, Pleasure D 1998 Hypoxic cell death in human NT2-N neurons: involvement of NMDA and non-NMDA glutamate receptors. J Neurochem 71:1544-1553

25. Munir M, Lu L, McGonigle P 1995 Excitotoxic cell death and delayed rescue in human neurons derived from NT2 cells. J Neurosci 15:7847-7860

26. Almaas R, Saugstad OD, Pleasure D, Rootwelt T 2000 Effect of barbiturates on hydroxyl radicals, lipid peroxidation and hypoxic cell death in human NT2-N neurons. Anesthesiology 92:764-774

27. Poulsen JP, Øyasæter S, Sanderud J, Rognum TO, Saugstad OD 1990 Hypoxanthine, xanthine, and uric acid concentrations cerebrospinal fluid, plasma, urine of hypoxemic pigs. Pediatr Res 28:477-481

28. Truelove D, Shuaib A, Ijaz S, Richardson S, Kalra J 1994 Superoxide dismutase, catalase, and U78517F attenuate neuronal damage in gerbils with repeated brief ischemic insults. Neurochem Res 19:665-671

29. Rootwelt T, Almaas R, Øyasæter S, Saugstad OD 1995 Release of xanthine oxidase to the systemic circulation during resuscitation from severe hypoxemia in newborn pigs. Acta Paediatr 84:507-511
30. Kleppner SR, Robinson KA, Trojanowski JQ, Lee VM 1995 Transplanted human neurons derived from a teratocarcinoma cell line (NTera-2) mature, integrate, and survive for over 1 year in the nude mouse brain. Comp Neurol 357:618-632

31. Borlongan CV, Tajima Y, Trojanowski JQ, Lee VMY, Sanberg PR 1998 Transplantation of cryopreserved human embryonal carcinoma-derived neurons (NT2N cells) promotes functional recovery in ischemic rats. Exp Neurol 149:310-321

32. Pauwels PJ, Opperdoes F, Trouet A 1985 Effects of antimycin, glucose deprivation, and serum on cultures of neurons, astrocytes, and neuroblastoma cells. J Neurochem 44:143-148

33. Monyer H, Hartley DM, Choi DW 1990 21-Aminosteroids attenuate excitotoxic neuronal injury in cortical cell cultures. Neuron 5:121-126

34. Mattson MP, Rychlik B, You JS, Sisken JE 1991 Sensitivity of cultured human embryonic cerebral cortical neurons to excitatory amino acid-induced calcium influx and neurotoxicity. Brain Res 542:76-106

35. Cazevieille C, Muller A, Meynier F, Bonne C 1993 Superoxide and nitric oxide cooperation in hypoxia/reoxygenation-induced neuron injury. Free Radic Biol Med 14:389-395

36. Martelin E, Palvimo JJ, Lapatto R, Raivio KO 2000 Nuclear factor Y activates the human xanthine oxidoreductase gene promotor. FEBS Lett 480:84-88

37. Lafon-Cazal M, Pietri S, Culcasi M, Bockaert J 1993 NMDA-dependent superoxide production and neurotoxicity. Nature 364:535-537

38. Dugan LL, Sensi SL, Canzoniero LMT, Handran SD, Rothman SM, Lin TS, Goldberg MP, Choi DW 1995 Mitochondrial production of reactive oxygen species in cortical neurons following exposure to $N$-methyl-D-aspartate. J Neurosci 10:6377-6388

39. Oliver CN, Starke-Reed PE, Stadtman ER, Liu GJ, Carney JM, Floyd RA 1990 Oxidative damage to brain proteins, loss of glutamine synthetase activity, and production of free radicals during ischemia/reperfusion-induced injury to gerbil brain. Proc Natl Acad Sci USA 87:5144-5147

40. Pellegrini Giampietro DE, Chierici G, Alesiani M, Carla V, Moroni F 1990 Excitatory amino acid release and free radical formation may cooperate in the genesis of ischemia-induced neuronal damage. J Neurosci 10:1035-1041

41. Aizenman E, Hartnett KA, Reynolds IJ 1990 Oxygen free radicals regulate NMDA receptor function via a redox modulatory site. Neuron 5:841-846

42. Ciani E, Grøneng L, Voltattorni M, Rolseth V, Contestabile A, Paulsen RE 1996 Inhibition of free radical production or free radical scavenging protects from the excitotoxic cell death mediated by glutamate in cultures of cerebellar granule neurons. Brain Res 728:1-6

43. Bredt DS, Glatt CE, Hwang PM, Fouhi M, Dawson TM, Snyder SH 1991 Nitric oxide synthase protein and mRNA are discretely localized in neuronal populations of the mammalian CNS together with NADP diaphorase. Neuron 7:615-624 